\title{
Absence of pro-survival A1 has no impact on inflammatory cell survival in vivo during acute lung inflammation and peritonitis
}

Marco Herold ( $\nabla$ herold@wehi.edu.au )

The Walter and Eliza Hall Institute of Medical Research https://orcid.org/0000-0001-7539-7581

\section{Lahiru Gangoda}

The Walter and Eliza Hall Institute of Medical Research

\section{Robyn Schenk}

The Walter and Eliza Hall Institute of Medical Research

\section{Sarah Best}

The Walter and Eliza Hall Institute of Medical Research https://orcid.org/0000-0002-4232-9432

\section{Christina Nedeva}

La Trobe University

\section{Cynthia Louis}

University of Melbourne

\section{Damien D'Silva}

University of Melbourne

Kirsten Fairfax

University of Tasmania

Andrew Jarnicki

University of Melbourne

Hamsa Puthalakath

La Trobe University https://orcid.org/0000-0001-5178-1175

\section{Kate Sutherland}

The Walter and Eliza Hall Institute of Medical Research https://orcid.org/0000-0002-7453-3366

\section{Andreas Strasser}

The Walter and Eliza Hall Institute of Medical Research

\section{Article}

Keywords: inflammation, A1, immunology

Posted Date: March 22nd, 2021

DOI: https://doi.org/10.21203/rs.3.rs-333716/v1 
License: (c) (i) This work is licensed under a Creative Commons Attribution 4.0 International License. Read Full License

Version of Record: A version of this preprint was published at Cell Death \& Differentiation on July 24th, 2021. See the published version at https://doi.org/10.1038/s41418-021-00839-3. 


\section{Abstract}

Inflammation is a natural defense mechanism of the body to protect against pathogens. It is induced by immune cells, such as macrophages and neutrophils, which are rapidly recruited to the site of infection, mediating host defense. The processes for eliminating inflammatory cells after pathogen clearance are critical in preventing sustained inflammation which can cause diverse pathologies. During chronic inflammation, excessive and uncontrollable activity of the immune system can cause extensive tissue damage. New therapies aimed at preventing this over-activity of the immune system could have major clinical benefit. Here, we investigated the role of the pro-survival Bcl-2 family member A1 in the survival of inflammatory cells under normal and inflammatory conditions using murine models of lung and peritoneal inflammation. Despite the robust upregulation of A1 protein levels in wild-type cells upon induction of inflammation, the survival of inflammatory cells was not impacted in A1 deficient mice compared to wild-type controls. These findings indicate that A 1 does not play a major role in immune cell homeostasis during inflammation and therefore does not constitute a therapeutic target for such morbidities.

\section{Introduction}

Inflammation is an important innate immune response which is usually activated by the ligation of pattern recognition receptors (PRRs) leading to upregulation of a broad range of pro-inflammatory factors, including cytokines and chemokines and migration of leukocytes from the circulation to the site of tissue damage ${ }^{1}$. The clearance of these cells once the infection or injury have been resolved is crucial for the tissue healing process. An inflammatory response that lasts only a few days is called acute inflammation, while a response of longer duration is referred to as chronic inflammation.

B-cell lymphoma 2 (BCL-2) family of proteins are the critical regulators of the intrinsic apoptotic pathway 2. However, A1 (in humans called BFL-1), remains a relatively poorly characterised anti-apoptotic protein 3. BCL2A1 (encoding A1) was first identified as an early response gene induced in bone marrow derived macrophages in response to treatment with granulocyte macrophage colony stimulating factor (GM-CSF) and lipopolysaccharide (LPS). This study also demonstrated that in mice, A1 expression is restricted to cells of the haematopoietic compartment ${ }^{3}$. In humans BFL-1 expression appears to be more widespread, but predominantly found in haematopoietic cells ${ }^{4}$. A1/BFL-1 expression can also be induced by inflammatory cytokines, such as tumour necrosis factor alpha (TNF $a$ ) and IL-1 ${ }^{5}$. The identification of $B C L 2 A 1$ as an NF-kB target gene ${ }^{6}$ and its expression in inflammatory cells suggest a role for $A 1$ during inflammation.

In mice, studies of $A 1$ is complicated by the prescence of three functional isoforms (A1-a, -b, - and -d) and a pseudogene (A1-C) ${ }^{7}$. Mice lacking the $A 1-a$ isoform displayed only minor defects in neutrophils and mast cells ${ }^{8,9}$. Recently mice lacking all three functional isoforms of $\mathrm{A} 1$ have been generated $\left(A 1^{-/-}\right.$mice $)$ 10. We utilised $A 1^{-/-}$mice to assess a role of $A 1$ in vivo upon specific inflammatory challenges. 
Neutrophils in the human blood are the first line defence against an infection. They are continuously released from their bone marrow reservoir, into the blood and are recruited to sites of infection. Circulating neutrophils have a short lifespan of only $7 \mathrm{~h}$ in the absence of infection ${ }^{11}$. This lifespan is extended after exposure to GM-CSF, granulocyte-colony stimulating factor (G-CSF) or diverse pathogen or damage associated molecular patterns, such as LPS ${ }^{12,13}$. Prolonged neutrophil survival and activity can be detrimental and their death is required for resolution of inflammation ${ }^{14}$.

The limited lifespan of neutrophils is partly due to their expression of pro- and anti-apoptotic proteins. Mcl-1 is critical for neutrophil survival under steady state ${ }^{15}$. Human neutrophils also express other antiapoptotic proteins, including BFL-1 ${ }^{16}$. Similar to Mcl-1, A1 is also a short-lived pro-survival protein. Here, we examined the role of $\mathrm{A} 1$ in neutrophil survival in models of inflammation in vivo.

\section{Results}

\section{A1 protein is strongly upregulated upon pro-inflammatory stimuli in vivo.}

A1 protein expression was analysed by Western blotting of lung tissues and peritoneal lavage cells from wild-type (WT) and $\mathrm{A} 1$ knockout $\left(A 1^{-/-}\right)$mice that had been challenged with indicated inflammatory stimuli using a previously characterised antibody ${ }^{17}$. Intranasal administration of LPS or Pseudomonas aeruginosa (PA) significantly upregulated A1 expression in the lungs of WT mice (Fig. 1a). Similarly, A1 expression was induced in the peritoneal exudate cells of WT mice following intraperitoneal (i.p.) injection of caecal slurry (CS) containing bacteria (Fig. 1a). The spleen was used as a distal organ control (Fig. 1a). LPS and many other constituents from bacteria stimulate PRRs which lead to the activation of $\mathrm{NF}-\mathrm{kB}$ signalling and hence, the upregulation of $\mathrm{A} 1$ expression. $\mathrm{A} 1$ expression was either absent or very low in the lung, spleen and peritoneal cells of naïve mice (Fig. 1a). We also assessed A1 expression following non-microbial stimuli in the monosodium urate (MSU)-induced peritonitis or ovalbumin-induced lung inflammation models demonstrating robust induction of A1 in both settings (Fig. 1b).

A1 has been shown to be important in regulating neutrophil survival in vitro ${ }^{18,19}$. Western blot analysis of isolated neutrophils from the lungs of LPS treated mice confirmed a marked upregulation of A1 in the enriched neutrophil fraction (Supplementary Fig. S1). This demonstrates that A1 is induced in neutrophils upon pro-inflammatory stimuli.

\section{Lack of A1 does not impact neutrophil survival during LPS induced lung inflammation}

Given the upregulated A1 expression in inflammatory neutrophils in vivo, we tested whether A1 is critical for neutrophil survival in this setting. Upon challenging WT and $A 1^{-/-}$mice with LPS intranasally, we observed increased immune cell infiltration in the lungs of LPS-challenged mice compared to PBS, demonstrating successful induction of lung inflammation (Fig. 2). Immune cell composition of lung tissues was further analysed by flow cytometry at $24 \mathrm{~h}$ post-treatment. No major differences were observed in the frequencies or numbers of B cells, T cells, macrophages or neutrophils in the lungs 
between WT and $A 1^{-/-}$mice (Fig. 2 and Supplementary Fig. S2) demonstrating that A1 is not required for survival of lung-infiltrating immune cells during inflammation. Gating strategy used for flow cytometry analysis of immune cells is shown in Supplementary Fig. S3.

\section{A1 deficiency causes a minor reduction in neutrophils during Pseudomonas aeruginosa induced lung inflammation}

The murine pulmonary PA infection model closely mimics bacterially-induced pneumonia in humans. Mice were intranasally administered with PA $\left(\sim 1.5 \times 10^{7} \mathrm{CFU}\right)$ to induce lung inflammation. Infected animals initially lose weight and show neutrophil-induced acute lung inflammation as the bacterial infection is rapidly cleared ${ }^{20,21}$. At $24 \mathrm{~h}$ post-infection, the lungs were analysed by flow cytometry to identify the infiltrating haematopoietic cell subsets. Infection with PA induced an influx of neutrophils (Fig. 3) and the frequencies of lung neutrophils from infected $A 1^{-/-}$mice were significantly lower than that of infected WT mice (Fig. 3). Observations during $24 \mathrm{~h}$ post-infection revealed similar weight loss but worse body condition in the $A 1^{-/-}$mice (Supplementary Fig. S4 a). In other mouse inflammatory models, (e.g. LPS, Mycobacterium bovis-derived Bacillus Calmette-Guerin (BCG), or Toxoplasma gondii) A1 is transiently upregulated during the first $8-16 \mathrm{~h}$ and at $24 \mathrm{~h}$ the levels of $A 1$ have declined $22,23,24$. This might explain why $A 1^{-/-}$mice display worse body condition during the first $12 \mathrm{~h}$ when their cells are more dependant on elevated $\mathrm{A} 1$ for survival. It is possible that during early time points, the absence of $A 1$ causes more infiltrating cells to die in the lungs and such debris may enhance inflammation and therefore, worse body conditions.

The clearance of the bacteria from the lungs was examined by flow cytometric analysis for internalised bacteria in granulocytes $\left(\mathrm{Gr}-1^{+}\right)$(Supplementary Fig. S4 b). Additionally, colony formation assays of lung extracts of PA-infected mice were performed to determine the number of bacteria (Supplementary Fig. S4 c). These assays did not show any difference in bacterial clearance between $A 1^{-/-}$and WT mice $24 \mathrm{~h}$ post-infection (Supplementary Fig. S4 c and d).

\section{A1 is not required for the accumulation of neutrophils during caecal slurry or LPS induced peritonitis}

Polymicrobial sepsis was induced in mice by i.p. injection of caecal contents of laboratory animals into test animals ${ }^{25}$. We assessed the onset of clinical signs, including reduced motor activity, lethargy, shivering, piloerection, rapid shallow breathing as well as systemic inflammatory cytokine levels.

We first determined the optimal concentration of CS to induce acute sepsis in mice. Doses below $0.5 \mathrm{~g} / \mathrm{kg}$ were non-lethal to mice at $24 \mathrm{~h}$ post-injection (Supplementary Fig. S5 a and b). In separate survival studies, mice were injected with lethal doses $(>0.5 \mathrm{~g} / \mathrm{kg}$ ) of CS (Fig. 4). We hypothesised that differences in neutrophil survival between WT and $A 1^{-/-}$mice would result in a difference in bacterial clearance and, consequently, in animal survival. Injection of $0.75 \mathrm{~g} / \mathrm{kg}$ or $1 \mathrm{~g} / \mathrm{kg}$ CS caused severe morbidity requiring 
euthanasia within $18-24 \mathrm{~h}$ in $100 \%$ of both WT and $A 1^{-/-}$mice. Treatment with $0.55 \mathrm{~g} / \mathrm{kg}$ CS caused severe disease in $28 \%$ and $43 \%$ of WT and $A 1^{-1-}$ mice, respectively, within $48 \mathrm{~h}$. Injection of $0.65 \mathrm{~g} / \mathrm{kg} \mathrm{CS}$ necessitated euthanasia of $38 \%$ and $88 \%$ of WT and $A 1^{-/-}$mice, respectively, at $48 \mathrm{~h}$ (Fig. 4). Despite these differences in survival at $48 \mathrm{~h}$ with $0.55 \mathrm{~g} / \mathrm{kg}$ and $0.65 \mathrm{~g} / \mathrm{kg}$ doses, the overall difference between survival curves did not reach statistical significance because animals of the two genotypes showed similar survival at later time points. Neutrophil mobilization from the bone marrow was observed at the minimum non-lethal dose of CS tested $(0.2 \mathrm{~g} / \mathrm{kg})$, but there was no difference between the WT and $A 1^{-/-}$ mice (Supplementary Fig. S6 a and b).

The peritoneal lavage, blood and bone marrow were obtained at $4 \mathrm{~h}$ and $18 \mathrm{~h}$ post-CS $(0.65 \mathrm{~g} / \mathrm{kg})$ injection for flow cytometry analysis (Fig. 5a and Supplementary Fig. S7). Although at $4 \mathrm{~h}$ there were no obvious differences between the different haematopietic cell populations of WT and $A 1^{-/-}$mice, by $18 \mathrm{~h}$ there were some differences, albeit slight (Fig. 5a and Supplementary Fig. S7). In the peritoneum of WT and $A 1^{-/-}$mice, the percentage of neutrophils significantly increased and the percentage of $T$ cells and macrophages significantly decreased at $4 \mathrm{~h}$ post-CS injection. As an additional model of peritoneal inflammation, we injected mice i.p. with LPS $(1 \mathrm{mg} / \mathrm{kg})$. Cells from the peritoneal lavage and blood were analysed by flow cytometry at $4 \mathrm{~h}$ post-injection. There was no difference in cell subset composition between WT and $A 1^{-/-}$mice injected with LPS. However, there was a significantly reduced frequency of peritoneal macrophages in PBS injected $A 1^{-/-}$mice compared to the WT mice (Fig. 5a). There was an increase in the percentage of neutrophils and a decrease in the percentage of lymphocytes in the blood of both WT and $A 1^{-/-}$mice upon LPS i.p. injection (Supp. Figure 8).

Increased infiltration of neutrophils to the site of infection may result in higher levels of inflammatory cytokines. The concentrations of inflammatory cytokines in the peritoneal lavage were determined by ELISA following injection of CS. The levels of TNF were slightly higher in $A 1^{-/-}$mice at $4 \mathrm{~h}$, and the levels of IL-1b were slightly lower in $A 1^{-/-}$mice at $18 \mathrm{~h}$ (Fig. 5b).

\section{Discussion}

Neutrophils are key players during inflammation. Neutrophil apoptosis during resolution of inflammation is necessary for their subsequent engulfment by macrophages ${ }^{26}$. We observed a strong upregulation of the pro-survival protein $A 1$ during pathogen-induced inflammation, both in the lungs and the peritoneal cavity of challenged mice. We further showed that A1 levels were increased in neutrophils and hypothesised that this increase in A1 protects neutrophils from premature apoptosis, thereby extending their life span.

We therefore investigated the role of $A 1$ in regulating neutrophil survival during inflammatory responses in vivo. Despite the upregulation of $\mathrm{A} 1$ in neutrophils in the lungs and peritoneal cavity during inflammatory responses, suprisingly, our findings indicate that A1 does not have a major role in regulating neutrophil survival at sites of inflammation. The absence of $A 1$ had no major impact on 
neutrophil mobilization/recruitment, pathogen clearance or inflammatory cell survival in response to diverse stimuli.

Neutrophils are highly sensitive to Fas-induced apoptosis ${ }^{12}$. The FasL-Fas induced apoptotic pathway also plays a role in the death of other immune cells, including B and T cells ${ }^{27}$. It has previously been reported that A1delays spontaneous and Fas ligand-induced apoptosis of activated neutrophils ${ }^{19}$ and $B$ cells ${ }^{28}$. Hence, the reason we did not observe a significant defect in neutrophils or B cells in our experiments with $A 1^{-/-}$mice could be due to its overlapping roles with other pro-survival proteins. Our data suggest that the role of $A 1$ in regulating immune cell survival during an inflammatory response is redundant and only becomes prominent in the absence of additional pro-survival proteins. This could be investigated in compound mutant mice that lack not only $\mathrm{A} 1$ but are also deficient for additional prosurvival BCL-2 family members (i.e. $\mathrm{A1}^{-/-} ; \mathrm{BCl}^{-X_{\mathrm{L}}+/-}, \mathrm{A1}^{-/-} ; \mathrm{BCl-2^{+/- }}$ and $\mathrm{A1}^{-/-} ; \mathrm{MCl}^{+/-}$).

Observations in $\mathrm{A} 1$ deficient mice during inflammation may not truly reflect the role of its homologue BFL-1 in humans. There are several differences between mouse A1 and human BFL-1. Mice have four A1 genes (three expressed, one pseudo-gene), whereas humans only have one $B C L 2 A 1$ gene ${ }^{7}$. These gene duplication events may have occurred and been preserved in evolution because different A1 proteins have designated roles in different tissues in mice ${ }^{3}$. In mice, A1 expression is restricted to cells of the haematopoietic compartment ${ }^{3}$ while in humans BFL- 1 expression is more widespread ${ }^{4}$.

Although neutrophils appear to express similar levels of all three functional A1 genes ${ }^{7}$, differential expression of these isoforms has been observed in other cell types. For example, A1-b is reported to be the predominant form in total thymocytes as well as in resting T and B cells. A1-a seems the least abundant isoform but one study reported its upregulation, alongside A1-d, upon TCR ligation in $C D 8^{+} \mathrm{T}$ cells ${ }^{29,30}$. Mouse A1 proteins are preferentially localized in the cytosol, whereas human BFL-1 can be found on the outer mitochondrial membrane. However, the pro-survival functions of A1 and BFL-1 appear to be independent of their localization, at least when overexpressed at high levels ${ }^{31,32}$.

The balance of lymphocytes and neutrophils is rather different between humans and mice: human blood is neutrophil rich ( 70\% neutrophils, 30\% lymphocytes), whereas mouse blood has a strong preponderance of lymphocytes ( $75 \%$ lymphocytes, $\sim 25 \%$ neutrophils) ${ }^{33}, 34$. If A1/BFL-1 is required for neutrophil survival during inflammation the functional consequences of its absence may be more prominent in humans.

The LPS induced murine lung inflammation model accurately mimics the neutrophilic inflammatory response seen in humans ${ }^{35}$. Administration of free-living PA to the murine lung results in either rapid bacterial clearance or acute overwhelming sepsis ${ }^{36}$. We modeled human intra-abdominal inflammation by using both LPS and CS i.p. injections.. LPS injection represents a model that is simple to use and highly reproducible ${ }^{37}$ where the host responds to bacterial products rather than the pathogen itself. There is a marked differences in the response to LPS between species. Rodents are relatively resistant to LPS, 
whereas humans and non-human primates show an enhanced response ${ }^{37}$. Compared to treatment with LPS, in the murine CS model, injection of free-living bacteria into mice promotes a lower but longer lasting increase in the levels of pro-inflammatory cytokines with more accurate manifestation of pathological changes that also occur in human sepsis ${ }^{38,39}$.

Despite the several models of inflammation used, we could not establish evidence for a critical involvement of $A 1$ during inflammation. As mentioned above, this could be largely due to its overlapping function with other and likely more dominant pro-survival proteins, such as Mcl-1 and Bcl-xL, which warrants testing of these models in compound mutant strains of mice.

\section{Methods}

\section{Mice}

All animal experiments were approved by The Walter and Eliza Hall Institute of Medical Research (WEHI) Animal Ethics Committee. The generation of $A 1^{-/-}$mice has been described previously ${ }^{10}$. All mouse strains have been generated on and were maintained on a C57BL/ 6 background and equal proportions of 7 to 8 week-old males and females were used in all experiments. The mice were transported and housed short term under specific pathogen-free conditions at the La Trobe Animal Research and Training Facility (LARTF) for PA and CS experiments.

\section{Intranasal injection of LPS}

Mice were slightly anaesthetized with Methoxyflurane. Anaesthetized mice received intranasal instillation of $10 \mu \mathrm{g}$ of LPS or an equivalent volume of PBS. Control mice only received PBS. The mice were placed under a heat lamp or on a heat pad and monitored until fully conscious.

\section{Intranasal administration of Pseudomonas aeruginosa}

Pseudomonas aeruginosa ATC27853 strain was grown overnight in $5 \mathrm{~mL}$ of LB broth. The bacteria were spun down and resuspended in PBS to obtain an $\mathrm{OD}_{600}$ of 0.7 . Mice were anaesthetized (similarly to the intranasal LPS experiments) and administered with $40 \mu \mathrm{L}$ of the solution containing of PA $(\sim 1.5 \times$ $\left.10^{7} \mathrm{CFU}\right)$ or $40 \mu \mathrm{L}$ of PBS.

\section{Induction of acute polymicrobial sepsis}

The CS injection method was used to induce polymicrobial sepsis . In brief, 50 naive wild-type adult C57BL/ 6 mice were euthanized and $10 \mathrm{~g}$ of ceacal content was harvested. The caecal content was resuspended in $5 \%$ dextrose to obtain a CS stock of $250 \mathrm{mg} / \mathrm{mL}$, which was then filtered through a 100 $\mu \mathrm{m}$ filter. This stock was aliquoted and stored and used for all CS experiments to prevent batch variations. Mice were injected with $0.1 \mathrm{mg} / \mathrm{kg}$ Buprenorphine $30 \mathrm{~min}$ before CS injection. Mice were i.p. 
injected with CS and monitored every $3 \mathrm{~h}$ up to first $72 \mathrm{~h}$ and then twice a day up to 2 weeks. Mice were euthanized if signs of distress were observed.

\section{Induction of inflammation by non-microbial components}

For the gout model, 2 mg of MSU crystals dissolved in PBS were i.p. injected into mice and peritoneal lavage obtained $16 \mathrm{~h}$ post-injection for Western blotting. For the acute asthma model, a suspension containing 20 ug ovalbumin (OVA) and $2.25 \mathrm{mg}$ aluminium hydroxide was injected i.p. into mice on day 1 and 14 and mice were aerosol challenged either with PBS or OVA for 15 min per day on days 21, 22 and 23. $24 \mathrm{~h}$ after the last exposure, mice were euthanized and organs harvested.

\section{Harvesting of cells from mice}

Mice were euthanized by $\mathrm{CO}_{2}$ asphyxiation. For bone marrow retrieval, the fermur was flushed with $1 \mathrm{~mL}$ of PBS buffer. Cells were passed through a $100 \mu \mathrm{m}$ cell strainer to obtain a single-cell suspension. For blood cell analysis, bleeds were taken from mice immediately following euthanasia into Microvette tubes containing anti-coagulants. For obtaining cells from the peritoneal cavity, mice were i.p. injected with 5 $\mathrm{mL}$ of cold PBS immediately following $\mathrm{CO}_{2}$ asphyxiation and gently massaged. The lavage containing the cells was drawn back into the syringe and the cells recovered by centrifugation.

Peritoneal cells were subjected to flow cytometry and the lavage fluid was used to measure cytokine levels by ELISA according to the manufacturer's instructions (eBioscience).

Lung tissues were minced, and tissue dissociation was carried out by enzymatic digestion (in medium containing $0.2 \mathrm{~g} / \mathrm{L}$ glucose and $20 \mathrm{mg} / \mathrm{mL}$ Worthington Collagenase Type 1) as previously described ${ }^{40}$. All processed cell pellets requiring red blood cell lysis were resuspended in lysis buffer $\left(0.156 \mathrm{M} \mathrm{NH}_{4} \mathrm{Cl}\right)$ and left at $25^{\circ} \mathrm{C}$ for $5 \mathrm{~min}$. The supernatant was removed, and the cells were resuspended in FACS buffer (PBS with $2 \%$ fetal calf serum) and stained with appropriate antibodies.

\section{Neutrophil isolation}

Neutrophils were isolated from the pellet of cells resulting from the processed lungs by using the Stem Cell Technologies' Mouse Neutrophil Enrichment Kit according to the manufacturer's instructions.

\section{p. aeruginosa colony formation assay}

The left lobe of the lung was dissected and homogenized in $1 \mathrm{~mL}$ of PBS. $20 \mu \mathrm{L}$ of the suspension was dropped on a LB agar plate as the undiluted sample. Subsequent dilutions were carried out in PBS and 20 $\mu \mathrm{L}$ from each of these dilutions was also dropped on the LB agar plates. Plates were incubated overnight at $37^{\circ} \mathrm{C}$ and the number of visible bacterial colonies counted the following day.

\section{Western blotting}


Total protein extracts were prepared by lysing cells in lysis buffer $(20 \mathrm{mM}$ Tris-pH 7.4, $135 \mathrm{mM} \mathrm{NaCl}, 1.5$ $\mathrm{mM} \mathrm{MgCl}_{2}, 1 \mathrm{mM}$ EGTA, 10\% (v/v) glycerol and 1\% (v/v) Triton-X-100; Sigma-Aldrich) with complete protease inhibitor cocktail (Roche) for $1 \mathrm{~h}$ at $4^{\circ} \mathrm{C}$. Equal amounts of proteins were electrophoresed on NuPAGE 4-12\% Bis Tris gels (Invitrogen) before transferring to nitrocellulose membranes (Life Technologies) and probing with primary antibodies: monoclonal rat anti-mouse A1 (clone 6D6, WEHI antibody facility, monoclonal-mouse anti-HSP70 (clone N6, W. Welch USCF). Secondary anti-rat/antimouse IgG antibodies conjugated to HRP (Southern BioTech, Birmingham, AL, USA) were applied, followed by Luminata Forte Western HRP substrate (Millipore, Billerica, MA, USA) for band visualisation. Membranes were imaged using the ChemiDoc XRS+ machine with ImageLab software (Bio-Rad).

\section{Statistical analysis}

Data are presented as the mean \pm s.e.m. Paired two-tailed student's $t$-test and $P$ values were used to determine statistical significance. $P$ values $<0.05$ were considered as statistically significant, and $P$ values $>0.05$ were considered non-significant. For mouse survival data analysis, the significance was calculated using the log-rank test (Prism Software, Graphpad).

\section{Haematopoietic cell analysis and flow cytometry}

Peripheral blood was analysed with the ADVIA automated haematology system (Bayer). Lung, bone marrow and peritoneal lavage cell populations were examined using flow cytometry. Cell populations were identified by staining with fluorochrome-conjugated monoclonal antibodies (produced in-house, BD Biosciences or BioLegend) that detect cell subset specific surface markers: B220 (BV605), TCRb (PE-Cy7), MAC-1 (FITC), GR-1 (APC) and Ly5.2 (PE). Dead cells were excluded from analysis by staining with propidium iodide ( $\mathrm{PI}, 5 \mu \mathrm{g} / \mathrm{mL}$ ). To determine the intracellular PA, cells were fixed and permeabalized using eBioscience intracellular fixation and permeabilisation buffer set and stained with Rabbit antiPseudomonas antibody (ab68538) followed by a FITC-conjugated anti-rabbit IgG secondary antibody. Flow cytometry was performed on the LSR II flow cytometer (BD Biosciences) and data were analysed using FlowJo software (FlowJo LLC).

\section{Declarations}

\section{Acknowledgements}

We acknowledge the invaluable contributions of the animal caretaker staff for animal husbandry and the flow cytometry facility of WEHI. This work was supported by grants and fellowships from the Australian National Health and Medical Research Council (NHMRC) (Project Grants 1186575, 1159658 and 1145728 to MJH, 1143105 to MJH and AS), Program Grant 1016701 to AS and Fellowships 1020363 to AS, 1156095 to MJH), the Leukemia and Lymphoma Society of America (LLS SCOR 7015-18 to AS and $\mathrm{MJH}$ ), the Cancer Council of Victoria (project grant 1147328 to $\mathrm{MJH}, 1052309$ to AS and Venture Grant to $\mathrm{MJH}$ and AS), the Australian Phenomics Network (to MJH), the Leukaemia and Lymphoma Society Grant \#7001-13 to AS; the estate of Anthony (Toni) Redstone OAM and The Craig Perkins Cancer Research 
Foundation; and operational infrastructure grants through the Australian Government NHMRCS IRIISS and the Victorian State Government Operational Infrastructure Support to AS and the CASS Foundation Science and Medicine Grant \#9393 to LG. KF is the recipient of the Alex Gadomski Fellowship, funded by Maddie Riewoldt's Vision.

\section{Author contributions}

L.G. performed and designed most experiments and wrote the manuscript; R.L.S., S.A.B., C.N., C.L., D.D. and K.F. helped to perform experiments and write the manuscript; A.J. H.P. and K.D.S. helped with discussions and advice on neutrophil experiments and write the manuscript; A.S. and M.J.H. planned the project, were involved in experimental design and helped to write the manuscript.

\section{Conflict of interest}

The authors declare that they have no conflict of interest.

\section{References}

1. Takeuchi O, Akira S. Pattern recognition receptors and inflammation. Cell 2010, 140(6): 805-820.

2. Yip KW, Reed JC. Bcl-2 family proteins and cancer. Oncogene 2008, 27(50): 6398-6406.

3. Vogler M. BCL2A1: the underdog in the BCL2 family. Cell Death Differ 2012, 19(1): 67-74.

4. Lin EY, Orlofsky A, Berger MS, Prystowsky MB. Characterization of A1, a novel hemopoietic-specific early-response gene with sequence similarity to bcl-2. J Immunol 1993, 151(4): 1979-1988.

5. Karsan A, Yee E, Kaushansky K, Harlan JM. Cloning of human Bcl-2 homologue: inflammatory cytokines induce human A1 in cultured endothelial cells. Blood 1996, 87(8): 3089-3096.

6. Zong WX, Edelstein LC, Chen C, Bash J, Gelinas C. The prosurvival Bcl-2 homolog Bfl-1/A1 is a direct transcriptional target of NF-kappaB that blocks TNFalpha-induced apoptosis. Genes Dev 1999, 13(4): 382-387.

7. Hatakeyama S, Hamasaki A, Negishi I, Loh DY, Sendo F, Nakayama K, et al. Multiple gene duplication and expression of mouse bcl-2-related genes, A1. Int Immunol 1998, 10(5): 631-637.

8. Hamasaki A, Sendo F, Nakayama K, Ishida N, Negishi I, Nakayama K, et al. Accelerated neutrophil apoptosis in mice lacking A1-a, a subtype of the bcl-2-related A1 gene. J Exp Med 1998, 188(11): 1985-1992.

9. Xiang Z, Ahmed AA, Moller C, Nakayama K, Hatakeyama S, Nilsson G. Essential role of the prosurvival bcl-2 homologue A1 in mast cell survival after allergic activation. J Exp Med 2001, 194(11): 1561-1569.

10. Schenk RL, Tuzlak S, Carrington EM, Zhan Y, Heinzel S, Teh CE, et al. Characterisation of mice lacking all functional isoforms of the pro-survival BCL-2 family member $\mathrm{A} 1$ reveals minor defects in the haematopoietic compartment. Cell Death Differ 2017, 24(3): 534-545. 
11. Summers C, Rankin SM, Condliffe AM, Singh N, Peters AM, Chilvers ER. Neutrophil kinetics in health and disease. Trends Immunol 2010, 31(8): 318-324.

12. O'Donnell JA, Kennedy CL, Pellegrini M, Nowell CJ, Zhang JG, O'Reilly LA, et al. Fas regulates neutrophil lifespan during viral and bacterial infection. J Leukoc Biol 2015, 97(2): 321-326.

13. Luo HR, Loison F. Constitutive neutrophil apoptosis: mechanisms and regulation. Am J Hematol 2008, 83(4): 288-295.

14. Koedel U, Frankenberg T, Kirschnek S, Obermaier B, Hacker H, Paul R, et al. Apoptosis Is Essential for Neutrophil Functional Shutdown and Determines Tissue Damage in Experimental Pneumococcal Meningitis. Plos Pathog 2009, 5(5).

15. Dzhagalov I, St John A, He YW. The antiapoptotic protein Mcl-1 is essential for the survival of neutrophils but not macrophages. Blood 2007, 109(4): 1620-1626.

16. Akgul C, Moulding DA, Edwards SW. Molecular control of neutrophil apoptosis. FEBS Lett 2001, 487(3): 318-322.

17. Lang MJ, Brennan MS, O'Reilly LA, Ottina E, Czabotar PE, Whitlock E, et al. Characterisation of a novel A1-specific monoclonal antibody. Cell Death Dis 2014, 5: e1553.

18. Vier J, Groth M, Sochalska M, Kirschnek S. The anti-apoptotic Bcl-2 family protein A1/Bfl-1 regulates neutrophil survival and homeostasis and is controlled via PI3K and JAK/STAT signaling. Cell Death Dis 2016, 7: e2103.

19. Schenk RL, Gangoda L, Lawlor KE, O'Reilly LA, Strasser A, Herold MJ. The pro-survival Bcl-2 family member A1 delays spontaneous and FAS ligand-induced apoptosis of activated neutrophils. Cell Death Dis 2020, 11(6): 474.

20. Kukavica-lbrulj I, Levesque RC. Animal models of chronic lung infection with Pseudomonas aeruginosa: useful tools for cystic fibrosis studies. Lab Anim 2008, 42(4): 389-412.

21. Bayes HK, Ritchie N, Irvine S, Evans TJ. A murine model of early Pseudomonas aeruginosa lung disease with transition to chronic infection. Sci Rep 2016, 6: 35838.

22. Kathania M, Raje Cl, Raje M, Dutta RK, Majumdar S. Bfl-1/A1 acts as a negative regulator of autophagy in mycobacteria infected macrophages. Int J Biochem Cell Biol 2011, 43(4): 573-585.

23. Kausalya S, Somogyi R, Orlofsky A, Prystowsky MB. Requirement of A1-a for bacillus CalmetteGuerin-mediated protection of macrophages against nitric oxide-induced apoptosis. J Immunol 2001, 166(7): 4721-4727.

24. Orlofsky A, Somogyi RD, Weiss LM, Prystowsky MB. The murine antiapoptotic protein A1 is induced in inflammatory macrophages and constitutively expressed in neutrophils. J Immunol 1999, 163(1): 412-419.

25. Doerflinger M, Glab J, Puthalakath H. Experimental In Vivo Sepsis Models to Monitor Immune Cell Apoptosis and Survival in Laboratory Mice. Methods Mol Biol 2016, 1419: 69-81.

26. Cox G, Crossley J, Xing Z. Macrophage engulfment of apoptotic neutrophils contributes to the resolution of acute pulmonary inflammation in vivo. Am J Respir Cell Mol Biol 1995, 12(2): 232-237. 
27. Russell JH, Rush B, Weaver C, Wang R. Mature T cells of autoimmune Ipr/lpr mice have a defect in antigen-stimulated suicide. Proc Natl Acad Sci U S A 1993, 90(10): 4409-4413.

28. Lee HH, Dadgostar H, Cheng Q, Shu J, Cheng G. NF-kappaB-mediated up-regulation of Bcl-x and Bfl1/A1 is required for CD40 survival signaling in B lymphocytes. Proc Natl Acad Sci U S A 1999, 96(16): 9136-9141.

29. Verschelde C, Walzer T, Galia P, Biemont MC, Quemeneur L, Revillard JP, et al. A1/Bfl-1 expression is restricted to TCR engagement in T lymphocytes. Cell Death Differ 2003, 10(9): 1059-1067.

30. Tuzlak S, Schenk RL, Vasanthakumar A, Preston SP, Haschka MD, Zotos D, et al. The BCL-2 prosurvival protein A1 is dispensable for T cell homeostasis on viral infection. Cell Death Differ 2017, 24(3): 523-533.

31. Ottina E, Tischner D, Herold MJ, Villunger A. A1/Bfl-1 in leukocyte development and cell death. Exp Cell Res 2012, 318(11): 1291-1303.

32. Herold MJ, Zeitz J, Pelzer C, Kraus C, Peters A, Wohlleben G, et al. The stability and anti-apoptotic function of $A 1$ are controlled by its $C$ terminus. J Biol Chem 2006, 281(19): 13663-13671.

33. Doeing DC, Borowicz JL, Crockett ET. Gender dimorphism in differential peripheral blood leukocyte counts in mice using cardiac, tail, foot, and saphenous vein puncture methods. BMC Clin Pathol 2003, 3(1): 3.

34. Mestas J, Hughes CCW. Of mice and not men: Differences between mouse and human immunology. Journal of Immunology 2004, 172(5): 2731-2738.

35. Wiener-Kronish JP, Albertine KH, Matthay MA. Differential responses of the endothelial and epithelial barriers of the lung in sheep to Escherichia coli endotoxin. J Clin Invest 1991, 88(3): 864-875.

36. Bragonzi A. Murine models of acute and chronic lung infection with cystic fibrosis pathogens. Int $J$ Med Microbiol 2010, 300(8): 584-593.

37. Murando F, Peloso A, Cobianchi L. Experimental Abdominal Sepsis: Sticking to an Awkward but Still Useful Translational Model. Mediators Inflamm 2019, 2019: 8971036.

38. Gonnert FA, Recknagel P, Seidel M, Jbeily N, Dahlke K, Bockmeyer CL, et al. Characteristics of clinical sepsis reflected in a reliable and reproducible rodent sepsis model. J Surg Res 2011, 170(1): e123134.

39. Lee MJ, Kim K, Jo YH, Lee JH, Hwang JE. Dose-dependent mortality and organ injury in a cecal slurry peritonitis model. J Surg Res 2016, 206(2): 427-434.

40. Best SA, Kersbergen A, Asselin-Labat ML, Sutherland KD. Combining Cell Type-Restricted Adenoviral Targeting with Immunostaining and Flow Cytometry to Identify Cells-of-Origin of Lung Cancer. Methods Mol Biol 2018, 1725: 15-29.

\section{Figures}


a

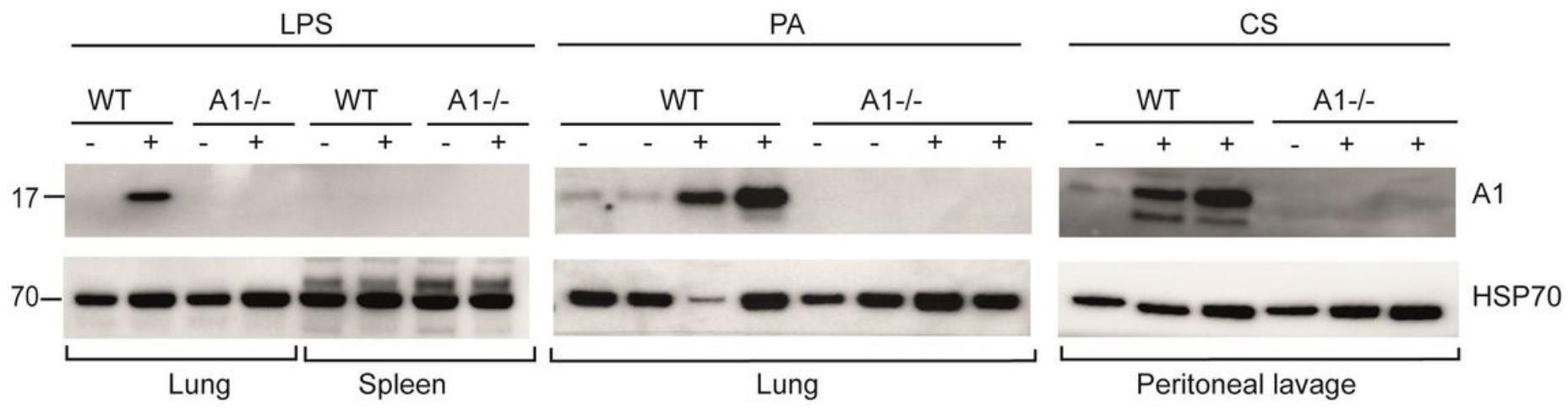

b

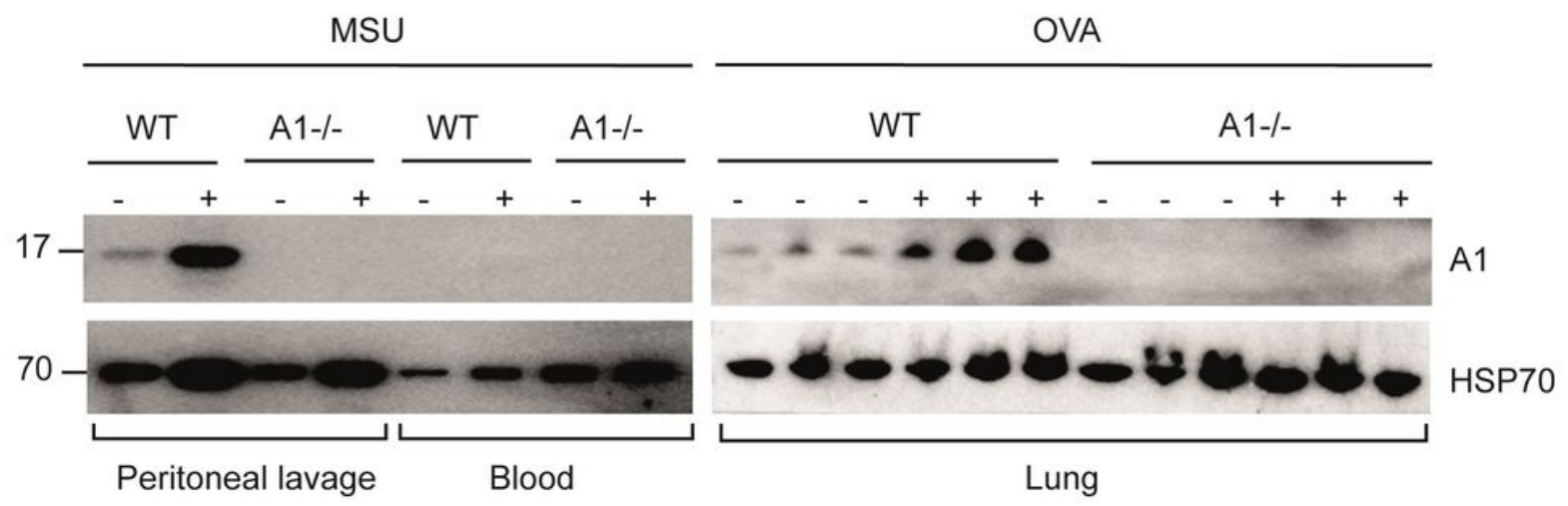

\section{Figure 1}

A1 protein expression in tissues and cells upon induction of inflammation by microbial and non-microbial stimuli. (a) WT and A1 knockout (A1-/-) mice were challenged with microbial components by either intranasally instillation of LPS, P. aeruginosa (PA) or i.p. injection with caecal slurry (CS). $24 \mathrm{~h}$ after these treatments, lung tissues or peritoneal lavage cells were harvested. (b) WT and A1-/- mice challenged with non-microbial components. Mice were i.p. injected with monosodium urate (MSU) crystals and peritoneal lavage was obtained at $24 \mathrm{~h}$ post injection. Mice were made to inhale Ovalbumin (OVA) and at the endpoint lung tissues were harvested. The lung and peritoneal lavage cells were analysed by Western blotting for A1 protein expression. Probing for Hsp70 was used as a loading control. 

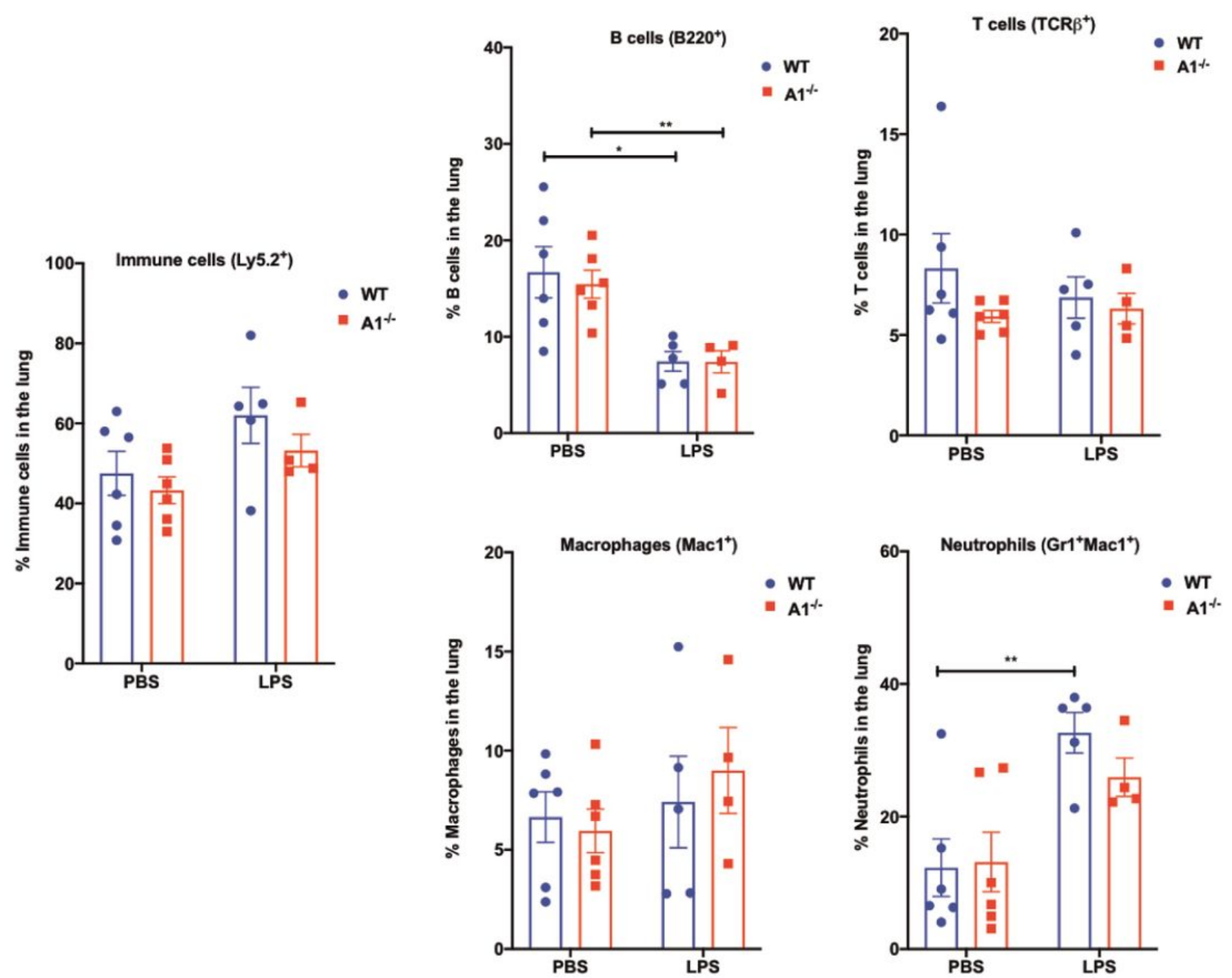

Figure 2

Analysis of immune cell populations in the lungs during LPS induced inflammation. WT and A1-/- mice were intranasally administered LPS $(10 \mu \mathrm{g})$ or vehicle (PBS). After $24 \mathrm{~h}$ lung tissues were harvested and processed, and percentages of cell subsets determined by flow cytometric analysis following staining for cell subset specific surface markers. Statistical significance $\left(P^{*}<0.05, P^{\star *}<0.01\right)$ was determined using student's t-test. Each dot represents one mouse. The gating strategy used for flow cytometric analysis is shown in Supplementary Fig. S3. 

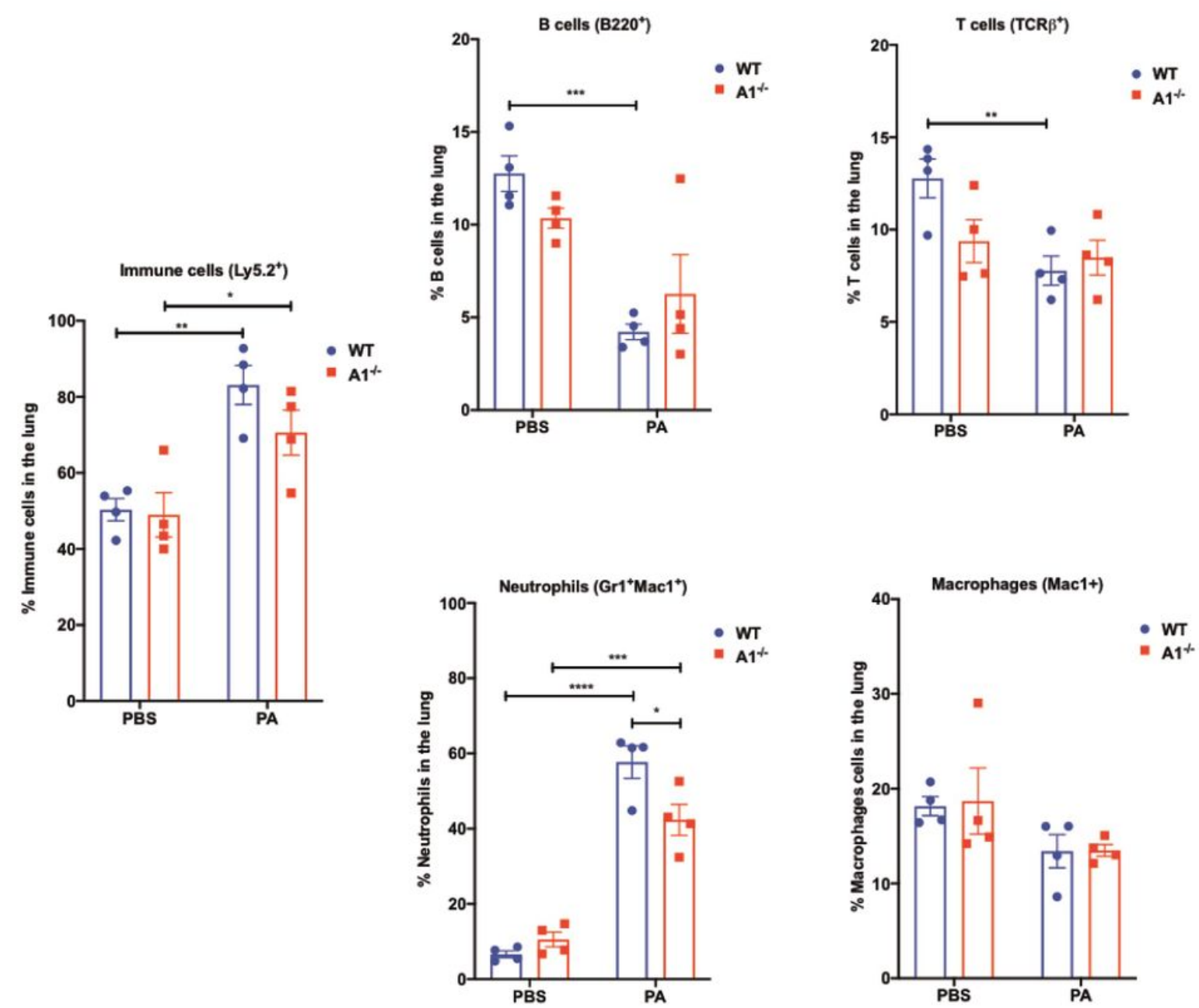

\section{Figure 3}

Analysis of the immune cell populations in the lungs during P.aeruginosa (PA) induced inflammation. WT and A1-/- mice were intranasally administered P. aeruginosa (PA) or vehicle (PBS). After $24 \mathrm{~h}$ lung tissues were harvested and processed, and percentages of cell subsets determined by flow cytometric analysis following staining for cell subset specific surface markers. Statistical significance $\left(P^{*}<0.05, P^{\star \star}<0.01\right.$, $P \star \star \star<0.001)$ was determined using student's t-test. Each dot represents one mouse. The gating strategy used for flow cytometric analysis is shown in Supplementary Fig. S3. 

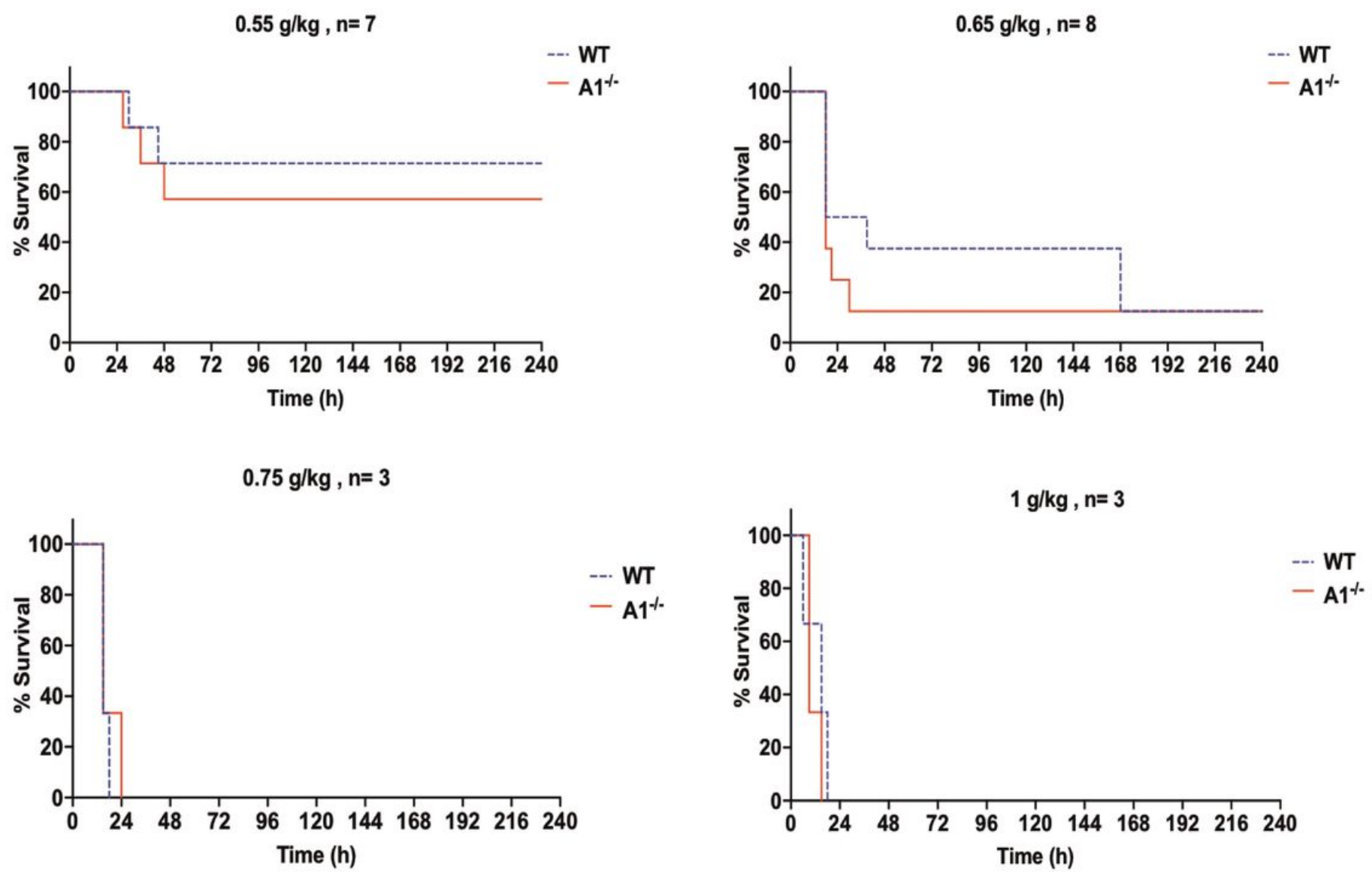

Figure 4

Kaplan-Meier curve presenting the survival of mice that had been injected with caecal slurry. Groups of WT and A1-/- mice were injected i.p. with different doses of caecal slurry doses and monitored every $3 \mathrm{~h}$ for up to 10 days and sacrificed when body condition scoring reached ethical endpoint. Overall survival graphs over the period of 10 days did not show any significant difference between WT and A1-/- mice at any of the doses. 


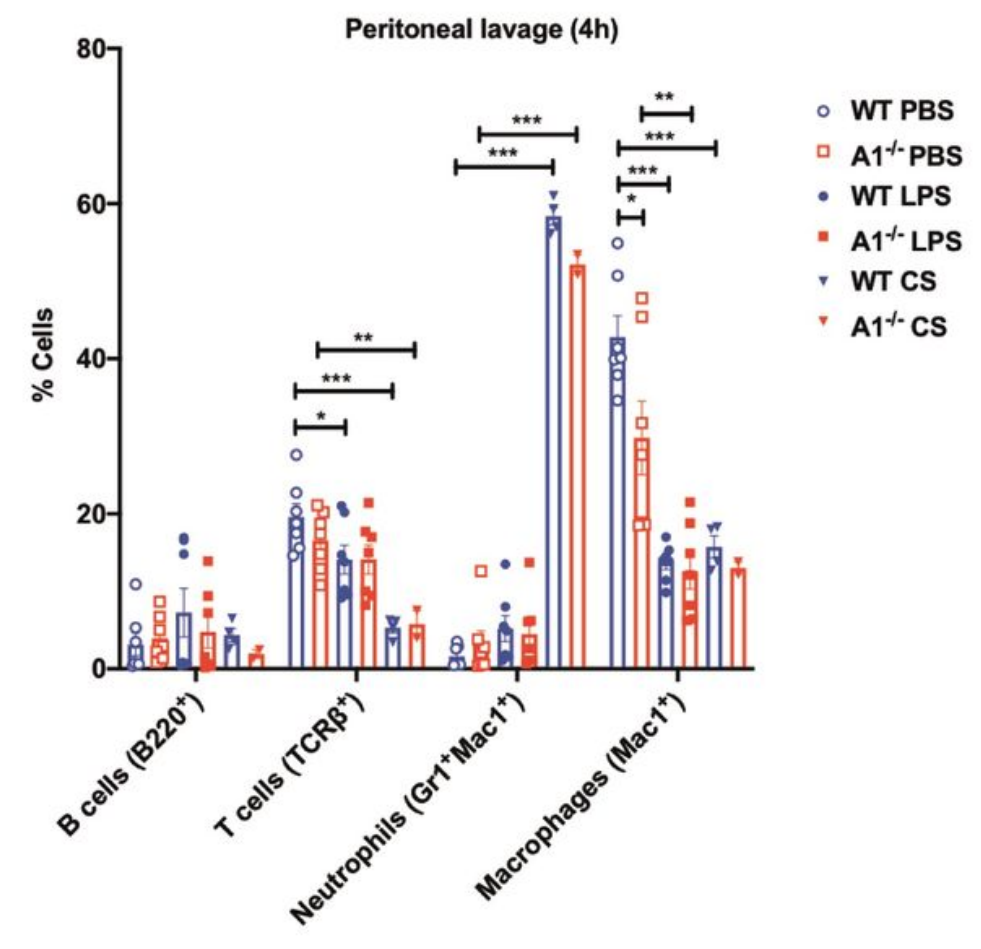

b
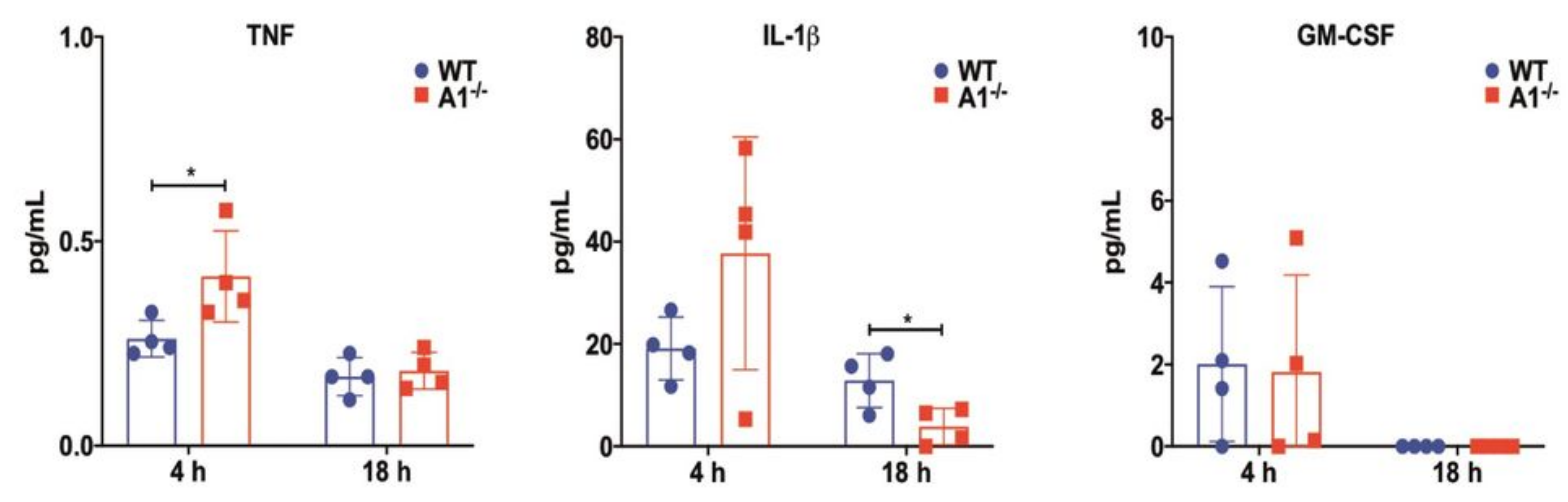

\section{Figure 5}

Analysis of the immune cell populations in the peritoneal lavage of caecal slurry and LPS injected mice. WT and A1-/- mice were injected i.p. with $0.65 \mathrm{~g} / \mathrm{kg}$ caecal slurry (CS) or $1 \mathrm{mg} / \mathrm{kg}$ LPS. Mice were sacrificed at $4 \mathrm{~h}$ post-injection. (a) Percentages of cell subsets in the peritoneal lavage were determined at $4 \mathrm{~h}$ after CS or LPS injection by flow cytometric analysis following staining for cell subset specific surface markers. The gating strategy used for flow cytometric analysis is shown in Supplementary Fig. S3. (b) Serum levels of TNF, IL-1B and GM-CSF from mice undergoing polymicrobial sepsis was 
measured by ELISA 4 and $18 \mathrm{~h}$ after injection with CS. Statistical significance $\left(P^{*}<0.05, P^{\star *}<0.01, P^{\star} \star *\right.$ $<0.001)$ was determined using student's t-test. Each dot represents one mouse.

\section{Supplementary Files}

This is a list of supplementary files associated with this preprint. Click to download.

- A1 inflammationSupplementaryGangoda.docx 